Original article

\title{
Community-based case control study on the risk of fall among elderly in Kaniyambadi block, Vellore, Tamil Nadu, India
}

\author{
Alex Joseph $^{\mathrm{a}, \mathrm{b}, *}$, Jayaprakash Muliyil ${ }^{\mathrm{a}}$ \\ ${ }^{\text {a }}$ Department of Community Health, Christian Medical College, Vellore, Tamil Nadu, 632004, India \\ ${ }^{\mathrm{b}}$ Division of Epidemiology, SRM School of Public Health, SRM Institute of Science and Technology, Kattankulathur, Tamil Nadu, India
}

\section{A R T I C L E I N F O}

\section{Keywords:}

Elderly

Falls

Injuries

Activities of daily living

Case control

\begin{abstract}
A B S T R A C T
Background: Fall injuries are a major cause of morbidity and disability in elderly. The magnitude of association of risk factors, the economic burden, and other consequences of fall in the elderly is less studied in India. Methods: A Community based matched case-control study was conducted among elderly $\geq 60$ years, elders with a history of fall in the past 1 year was identified as cases. One control per case were selected, each case and control were matched for age and gender. Both groups were randomly selected from older people (age $\geq 60$ ) living in Kaniyambadi block identified by door-to-door survey. Univariate analysis, stratified analysis and multivariate analysis was performed.

Results: Having 141 cases of fall among 776 elders contacted, 18.17\% (15.6-21.1) was estimated as the incidence of fall. The independent risk factors were identified as dizziness OR 2 (1.3 to 3.8) times and difficulty in walking OR 3 (1.7 to 5.9) times more likely for fall. Certain risk factors were found to be different in men and women. Among the 141 falls 110 (78\%) had economic burden due to fall. Rs. 2370 was the mean expense for a fall, maximum of Rs 33,000 to a minimum of Rs 10 were spent because of falling.

Conclusion: This study was one of the first community bases case-control studies in India on the risk of fall in elderly people. The study provides the important information on risk and protective factors for fall in rural Indians. The information could be used to develop targeted interventions to prevent the fall in this vulnerable age group.
\end{abstract}

\section{Introduction}

Falls are characterized as "Carelessly coming to rest on the floor, ground or other lower level, without intentional change in position to rest on the wall, furniture or other objects". (WHO global report about falls). They were implied as E880-E888 in ICD-9 and W00-W19 in ICD10 , consisting of a broad range of fuels, including those of higher, same levels and unnamed falls. ${ }^{1}$

The incidence of falls also seems to vary between countries. Every year, almost $28-35 \%$ of those aged 65 or older suffer from a fall. The fall rate upsurges with frailty level and age as per WHO Global Report. Falls are important, and it is forgotten, therefore, reported frequencies of falling differ rendering to the ascertainment technique used.

India is having the 2nd largest population after China in terms of elderly people, which constitute 80 million in population. India's elderly population is growing faster than the general population. The 1991 Census showed $6.58 \%$ of the total population belonged to the above 60 age group. According 2001 census the elderly people were around $7.45 \%$ of the total population are expected to grow to $9.87 \%$ by 2021 .

The study was conducted in the field practice area of Christian Medical College, Vellore, Kaniyambadi block, Vellore district, Tamil Nadu. In the year 2010, the Kaniyambadi block comprised of a total population of 106,993 permanent residents, with a male/female ratio of 1000:1002. Out of the total population, $100.2 \%$ were aged 60 years and above.

Injuries resulting from falls in elderly people are a primary publichealth concern, and it is considered as one of the main reasons of functional impairment, long standing pain, disability, and death in this population.

\footnotetext{
* Corresponding author. SRM School of Public Health, SRM Institute of Science and Technology, Kattankulathur, 603203, Tamil Nadu, India.

E-mail addresses: alexjosephdr@gmail.com (A. Joseph), jpmuliyil@gmail.com (J. Muliyil).
} 


\section{Methodology}

\subsection{Ethical consideration}

The protocol was approved by the Research \& Ethics Committees (IRB) of Christian Medical College, Vellore, IRB/RC Min No: 7160. Informed consent was obtained in regional language after clearly explaining the study objectives to the participants.

\subsection{Sample size}

To calculate the sample-size, the relative frequency of exposure among the controls in the target population (P0) was considered as 0.5. The hypothesized relative risk associated with exposure that would be of sufficient public health importance to warrant its decision (R) was estimated as 2 . The desired level of significance, or the probability of type I error $(\alpha)$ as 0.05 . The probability permitted for making Type II error $(\beta)$ as 0.2 .

The sample size was calculated using the following formula $(\mathrm{n})=$ $2 \mathrm{PQ}(\mathrm{Z} \alpha+\mathrm{Z} \beta)^{2} /(\mathrm{P} 1-\mathrm{P} 0)^{2}$ where, $\mathrm{P} 1=\mathrm{P} 0 \mathrm{R} /[1+\mathrm{P} 0(\mathrm{R}-1)]$ and, $\mathrm{P}=1 / 2$ $(\mathrm{P} 1+\mathrm{P} 0) ; \mathrm{Q}=1-\mathrm{P}$.

A sample size of was calculated to be 136 cases and 136 controls, we sampled 141 cases and 140 controls, to a total sample size of 281 .

\subsection{Sampling method}

Individuals residing in the area who are $\geq 60$ years, with any history of fall during past 1 year were identified as cases. These individuals should have been mobile, independent and without any serious illness before the fall. The cases were identified by door-to-door interview.

Individuals who are $\geq 60$ years, without the history of fall during the past 1 year and without any obvious illness from the neighborhood were randomly selected as controls. Single control per case was selected.

\subsection{Content of the questionnaire}

The participants were asked questions about their perception on fall and what they thought to be the risk factors and what prevents falling. The information thus obtained was included in the questionnaire, apart from information on demographic details and the known risk factors for falling. All the variables were self-reported, and no tests were performed were used to verify the same.

\subsection{Data analysis}

The raw data was entered in Epi Info 2002 (CDC, 2002; Database and Statistics Software for Public Health Professionals) and was verified by the primary investigator.

Analysis of the data was done using the SPSS Inc. Released 2007. SPSS for Windows, Version 16.0. Chicago, SPSS Inc. Initially an unmatched univariate analysis was carried out, followed by a stratified analysis. The factors that were statistically significant were considered for multivariate analysis and a model was derived.

\section{Results}

\subsection{Statistical results}

In the survey carried out, 776 elderly were contacted from 8 villages, selected randomly. 141 elderly were reported to have fallen at least one fall in the past one year in the 776 elders contacted, $141 / 776=18.17 \%$ (15.6-21.1) was estimated as the incidence of fall in people in the past one year in Kaniyambadi block. Fig. 1 shows events of fall among the 141 cases, 83 (58\%) cases had only one fall, $49(34.8 \%)$ had 2 falls and 9 (6.4\%) had more than 3 falls in the last one year a total of 208 events. The incidence rate was calculated as $(208 / 776) \times 100=26.80$ per

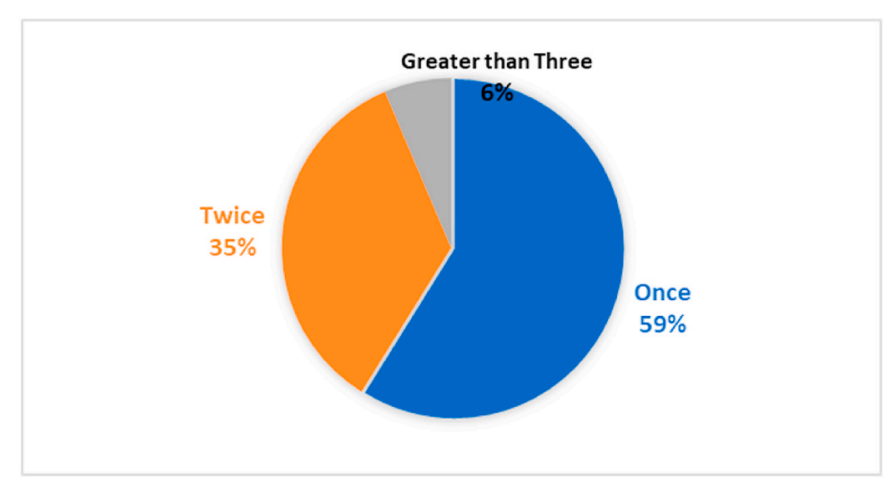

Fig. 1. Number of fall events.

hundred person years.

Table 1 shows, among the total 141 cases, there were 35 (25\%) who met with a fall in indoor area, out of all the falls 75 (53.2\%) meet with a fall while walking, $35(24.8 \%)$ met with fall while doing vigorous activities (walking bearing weight or running), and 31 (22\%) meet with fall while negotiating stairs, walking up or down the staircase.

Among the perceived causes of fall in cases, 61 (43.3\%) fall because they walked on uneven surface, $29(20.6 \%)$ slipped and fallen, 28 (19.9\%) tripped and fallen. Only 6 (4.3\%) were reported to fallen after the consumption of alcohol.

The $102(72.3 \%)$ have experienced subjective premonitory feelings before fall, weakness of limbs 59 (41.8\%), followed by 22 (15.6\%) with giddiness, 8 (5.7\%) experienced vertigo, 8 (5.7\%) experienced dimness of vision and $5(3.5 \%)$ experienced chest pain, immediately before fall.

Table 2 represents the type of injury sustained as the consequence of the fall. Among all the 141 fallers 136 (96.4) sustained injuries, most common injury was pain and bruises $51(36.1 \%)$, followed by fracture 31 (22\%), 26 (18.4\%) with minor cuts, 20 (14.1\%) with dislocation and 8 (5.6\%) sustained head injuries.

The most common part injured was found to be, injury in leg 45 (33\%), followed by injuries on hand $42(30.8 \%), 11$ (8\%) with knees injuries, $11(8 \%)$ had hip injuries and $5(3.6 \%)$ with wrist injury. Among the 141 fallers, 119 (84.3\%) availed medical attention, visit to allopathic doctor was the most common practice $95(79.8 \%)$, followed by 18 $(15.1 \%)$ required hospitalization, and $6(5 \%)$ visited traditional healers to avail medical attention after fall. Among the fallers, 64 (45.4\%) daily activities were not affected, they were able to move around freely, 47 $(33.3 \%)$ had restricted activity and $30(21.3 \%)$ were bedridden after the fall.

\subsection{Analytical statistics}

Among the participants, 149 (53\%) were females and 132 (47\%) males, The age of the cases ranged from 50 to 91 years, with a median (interquartile range) age of 70 (65-75) years, with a mean age of 69.62 The age of the controls ranged from 60 to 85 years with a median (interquartile range) age of $68.50(63.50-73.50)$ years with a mean age of 69.5. Since the cases and controls were matched for age and gender. There was no significant difference in age and gender between cases and

Table 1

Place of fall.

\begin{tabular}{llll}
\hline Place of fall & & Frequency & Percent \\
\hline Indoor & Inside house & 28 & 20.0 \\
& Bathroom & 7 & 5.0 \\
& (Total indoor) & $(35)$ & $(25)$ \\
Outdoor & Open field & 62 & 44.0 \\
& Road & 44 & 31.2 \\
& (Total outdoor) & $(102)$ & $(75)$ \\
Sub Total & & 141 & 100.0 \\
\hline
\end{tabular}


Table 2

Type of injury sustained.

\begin{tabular}{llll}
\hline Type of injury & Frequency & Valid Percent & Cumulative Percent \\
\hline Pain \& bruises & 51 & 36.1 & 36.1 \\
Minor cut & 26 & 18.4 & 54.5 \\
Dislocation & 20 & 14.1 & 68.7 \\
Fracture & 31 & 21.9 & 90.6 \\
Head Trauma & 8 & 5.6 & 96.2 \\
No injuries & 5 & 3.5 & 100 \\
Total & 141 & 100.0 & 100 \\
\hline
\end{tabular}

controls as expected.

Religion, type of family, occupation, type of housing, economic dependence, use of any nutrient supplements, being on vegetarian diet did not show significant difference between the cases and controls. However, in education 154 (54.8\%) were illiterates, 63 (22.4\%) having Primary school (0-5) education, $28(10.0 \%)$ having Middle school ${ }^{6-8}$ education, 36(12.8\%) with High school and above $(>8)$. P value of 0.028 suggests having a significant difference in educational status between cases and controls.

Table 3 shows Crude odds ratio with 95\% CI for selected protective and risk factors, using unconditional logistic regression. After adjusting for odds ratio we found that using of Walking Aid Crude OR 2.7; 95\% CI (1.4-5.4), Difficulty in Negotiating Stairs crude OR of $1.7 ; 95 \%$ CI (1.0-2.7), Fear of Fall crude OR of 2.0; 95\% CI, (1.0-3.9), Difficulty in

Table 3

Crude odds ratio with $95 \%$ CI for selected protective and risk factors, using unconditional logistic regression.

\begin{tabular}{|c|c|c|c|c|}
\hline \multicolumn{2}{|l|}{ Variable } & $\begin{array}{l}\text { Crude } \\
\text { OR }\end{array}$ & $95 \%$ CI & Significance \\
\hline \multicolumn{2}{|c|}{ Difficulty In Negotiating stairs } & 1.7 & $(1.0-2.7)$ & Significant \\
\hline \multicolumn{2}{|c|}{ Fear of Falling } & 2.1 & $(1.0-3.9)$ & Significant \\
\hline \multicolumn{2}{|c|}{ Difficulty in Walking } & 3.8 & $(2.2-6.6)$ & Significant \\
\hline \multicolumn{2}{|c|}{ Decreased Sensation of foot } & 2.1 & $(1.0-4.7)$ & Significant \\
\hline \multicolumn{2}{|c|}{ Visual Device(spectacles) } & 1.1 & $(.64-1.9)$ & $\begin{array}{l}\text { Not } \\
\text { Significant }\end{array}$ \\
\hline \multicolumn{2}{|l|}{ Exercise (Yes) } & .75 & $(.37-1.6)$ & $\begin{array}{l}\text { Not } \\
\text { Significant }\end{array}$ \\
\hline \multicolumn{2}{|c|}{ Economic dependence (Dependent) } & 1.5 & $(.89-2.6)$ & $\begin{array}{l}\text { Not } \\
\text { Significant }\end{array}$ \\
\hline \multirow[t]{3}{*}{$\begin{array}{l}\text { Marital } \\
\text { status: }\end{array}$} & Living together & 1.5 & $(.50-4.7)$ & $\begin{array}{l}\text { Not } \\
\text { Significant }\end{array}$ \\
\hline & Widow/widower & .93 & $(.57-1.5)$ & $\begin{array}{l}\text { Not } \\
\text { Significant }\end{array}$ \\
\hline & $\begin{array}{l}\text { Separated/Never } \\
\text { Married }\end{array}$ & $1^{\mathrm{a}}$ & & \\
\hline \multirow{3}{*}{$\begin{array}{l}\text { Type of } \\
\text { Family }\end{array}$} & Nuclear & $1^{\mathrm{a}}$ & & \\
\hline & Extended & .42 & $(.13-1.4)$ & $\begin{array}{l}\text { Not } \\
\text { Significant }\end{array}$ \\
\hline & Joint & 1.6 & $(.88-2.9)$ & $\begin{array}{l}\text { Not } \\
\text { Significant }\end{array}$ \\
\hline \multirow[t]{3}{*}{ Type of house } & Hut/Katcha & 1.5 & $(.84-2.5)$ & $\begin{array}{l}\text { Not } \\
\text { Significant }\end{array}$ \\
\hline & Mixed & .75 & $(.41-1.4)$ & $\begin{array}{l}\text { Not } \\
\text { Significant }\end{array}$ \\
\hline & Cemented & $1^{\mathrm{a}}$ & & \\
\hline \multirow[t]{4}{*}{ Occupation } & Unemployed & 1.3 & $(.46-3.8)$ & $\begin{array}{l}\text { Not } \\
\text { Significant }\end{array}$ \\
\hline & Unskilled Laborer & .86 & $(.28-2.6)$ & $\begin{array}{l}\text { Not } \\
\text { Significant }\end{array}$ \\
\hline & Laborer Skilled & .57 & $(.08-4.1)$ & $\begin{array}{l}\text { Not } \\
\text { Significant }\end{array}$ \\
\hline & Business & $1^{\mathrm{a}}$ & & \\
\hline \multirow[t]{4}{*}{ Education } & Illiterate & 1.19 & $(.58-2.5)$ & $\begin{array}{l}\text { Not } \\
\text { Significant }\end{array}$ \\
\hline & Primary school & .55 & $(.24-1.3)$ & $\begin{array}{l}\text { Not } \\
\text { Significant }\end{array}$ \\
\hline & Middle school & .49 & $(.18-1.4)$ & $\begin{array}{l}\text { Not } \\
\text { Significant }\end{array}$ \\
\hline & High school \& above & $1^{\mathrm{a}}$ & & \\
\hline
\end{tabular}

Walking crude OR of 3.8; 95\% CI, (2.3-6.6) and Decreased Sensation of Foot crude OR of $2.1 ; 95 \%$ CI $(1.0-4.8)$ were found to be statistically significant in the case control study. We also observed the following risk factors; Number of rooms in house, Vegetarian diet, having no Nutritional supplements, Wearing spectacles, Insufficient lighting in rooms, Slippery bathroom floor, having a separate room and being economically dependent, doing exercise showed no significant difference and was underpowered. Socio demographic status like type of family, occupation, marital status, and education were not statistically significant.

\subsection{Multivariate analysis}

The data were analyzed using unconditional logistic regression to perform multivariate analysis. The analysis included selected variables with a p-value below 0.05 . In various models, the link between these variables was studied.

The factors that were statistically significant or nearing to significance were considered for multivariate analysis. The logistic regression analysis showed that dizziness and difficulty in walking to be significant predictors for falling in elderly, crude odds ratios were 2.3 (95\% confidence interval (CI) 1.3 to 3.8 ) and 3.9 (95\% CI 1.7 to 5.9) respectively. Elderly who had dizziness were 2 times more likely to have risk of fall and elderly who had difficulty in walk were 3 times more likely have risk of fall. While use of walking aid, difficulty in negotiating stairs/steps, fear of falling, decreased sensation of foot doing physical activity was associated with risk of fall but it didn't reach statistical significance as independent risk factors as per the Table 4.

\subsection{Economic burden of fall}

Among the 141 falls, 31 (22\%) falls did not have any economic burden associated with falling. The $110(78 \%)$ had economic burden due to the fall, Rs. 2370 was the mean expense for a fall, including both direct and indirect expenses. Maximum of Rs 33,000 and a minimum of Rs 10 were spent because of falling. Fig. 2 shows the distribution of the cost associated with fall injuries in the elderly.

The direct medical cost includes the following hospitalization, clinician visits, diagnostic testing, therapeutic procedure, and drug treatments. Rs.1722 was the mean cost of direct medical expenses, with a minimum of Rs 1 to a maximum of Rs 27,000 spent towards meeting the direct medical expenses.

Direct non-medical costs associated with treatment, such as transportation costs for to and from medical services Rs 427 was the mean cost for indirect medical expenses, with a minimum of Rs 10 and maximum of Rs 10,000 spent towards meeting the indirect medical expenses.

Indirect nonmedical cost involves loss of wages for the patient as well as the bystander, Rs 315 was the mean cost of indirect non-medical expenses, with a minimum of Rs 50 and maximum of Rs 6000 spent towards meeting the indirect medical expenses.

Table 4

Risk factor analysis for fall using unconditional multiple logistic regression.

\begin{tabular}{|c|c|c|c|c|}
\hline \multirow[t]{2}{*}{ Parameter } & \multirow[t]{2}{*}{ Crude OR } & \multirow[t]{2}{*}{ Adjusted OR } & \multicolumn{2}{|c|}{$\begin{array}{l}\text { 95\% Confidence } \\
\text { Interval for OR }\end{array}$} \\
\hline & & & Lower & Upper \\
\hline Decreased sensation of foot & 2.1 & 2.1 & 0.9 & 4.9 \\
\hline $\begin{array}{l}\text { Difficulty in negotiating stairs/ } \\
\text { steps }\end{array}$ & 1.7 & 1.0 & 0.6 & 1.8 \\
\hline Fear of falling & 2.0 & 1.5 & 0.7 & 3.1 \\
\hline Dizziness & 2.3 & 2.3 & 1.3 & 3.8 \\
\hline Use Of Walking Aid & 2.7 & 1.1 & 0.5 & 2.5 \\
\hline Difficulty in walking & 3.9 & 3.2 & 1.7 & 5.9 \\
\hline Physical activity & 0.54 & 0.6 & 0.35 & 1.0 \\
\hline
\end{tabular}




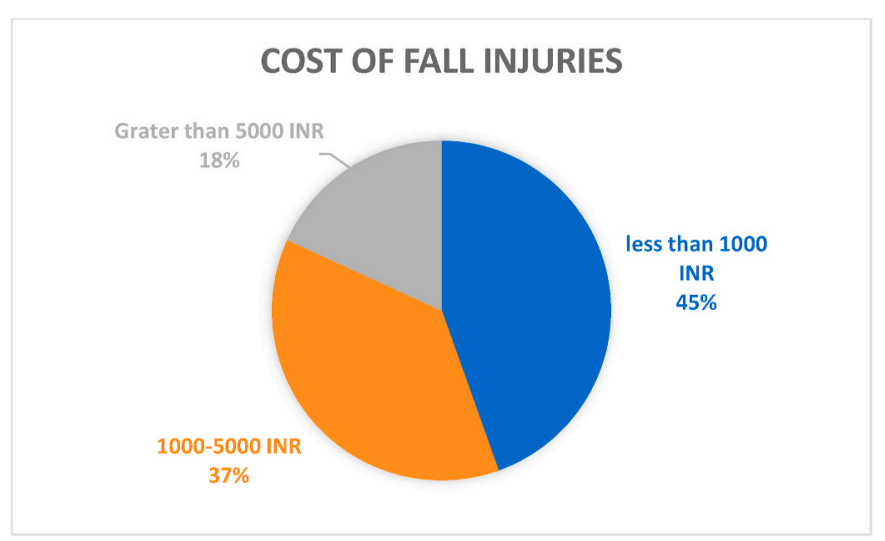

Fig. 2. Economic burden.

\subsubsection{Discussion}

In acute, non-acute care settings and in the community, falls and related injuries are a serious clinical and public health problem. Fall related injuries continue to be a key health concern in developed countries for adults over 65 years of age. More than one third of older people fall annually and $10 \%-20 \%$ are prone to serious injuries such as fractures or head trauma. ${ }^{2-5}$ The result of a fall can lead either to dislocations, no injuries, bruises or lacerations, fractures and head injuries, including traumatic or traumatic wounds or in some cases to death. ${ }^{6}$ Traumatic complications have increased hospitalization rates among fallers; in addition, recovery from fall injury is frequently delayed. A substantial share of falls, particularly non-traumatic injuries, are not reported, but aging instability is a natural event. ${ }^{7}$ If the risk of future fall is increased, the QOL is decreased. ${ }^{8}$ Older people are frequently injured leading to morbidity and mortality, loss of independence and poor quality of life. ${ }^{9}$ Injurious falls in elderly people can cause high disabilities and mortality, leading to extended hospitalization and increased medical costs. ${ }^{10}$ With the growth of global longevity, the health and falling costs are sure to increase. ${ }^{11}$ The risk of injury increases due to organ fragility and the recovery time is proceeding slowly. ${ }^{12}$ However, falls are preventable in the majority of cases. The risk assessment and, if possible, the modification of risk factors will entail effective fall prevention for the elderly. ${ }^{13,14}$ Fall prevention must be taken into account in public health policies and elderly health programs. ${ }^{15}$ Regular training increases the strength of muscles, coordination and flexibility and reduces the falls. ${ }^{16}$ To the best of our knowledge, being the one of the first community-based case-control study on the risk factors for fall among elderly in India.

\subsubsection{Risk factors for fall}

3.4.2.1. Physical activity. Moderate exercise and physical activities reduce the possibility of falls and fall-related injuries in older age by maintaining weight gain and by contributing to healthy bones, strong muscles, and joints. ${ }^{17}$ In this study, physical activity was found to minimize the risk of falling by $45 \%$.

3.4.2.2. Dizziness. Dizziness is commonly reported by elderly persons who have had a fall and has been attributed to be the primary cause in falls. ${ }^{18}$ In the study, an elderly person with dizziness was found to have 2.29 times higher risk of falling, which was statistically significant. This risk increased with age, the possibility of falling, increasing seven-fold for people aged 80 and above.

3.4.2.3. Multiple medications. Uncontrolled medical conditions and non-adherence to prescribed medication can alter alertness levels, judgment, and coordination. ${ }^{19}$ In the study, although cases were 1.26 more probable to use multiple medications than controls, it was not statistically significant.

3.4.2.4. Consumption of alcohol. Harmful consumption of alcohol increases the risk of falls. In this study, the cases were 1.58 times more likely to consume alcohol than the controls. When the cases and controls were stratified by gender, males with a history of falls were twice as likely to consume alcohol as those without. Similar high alcohol usage among elderly males was found from have been reported from another study in Kaniyambadi block. ${ }^{20}$

3.4.2.5. Perceived difficulty in vision. Vision plays an important role in stabilizing equilibrium by providing constantly updated information on the position and motions of body segments in connection with one another and the environment. ${ }^{21}$ Interestingly, in this study, people with a difficult vision had 1.28 higher risk of falling, even if it was not statistically significant. In the stratified analysis, among individuals with visual difficulty, people who had difficulty in vision, even with spectacles were $2.3 \mathrm{x}$ more expected to have a history of fall, which was statistically significant.

\section{Conclusion}

This community-based case-control study was undertaken to identify the factors associated with the risk of fall in the elderly with age $\geq 60$ years among elderly, and its consequences in a rural Indian population. Even though the majority had single event of a fall in the one year, almost same had multiple events too, which was almost nearing to half of the total fallers. Most of them happen to have outdoor falls, common environmental risk was contributed to walking on uneven surfaces, most had fall from same standing height, commonly fallen forwards. A very high proportion reported to have experienced premonitory subjective symptoms before the fall, commonly experienced as weakness of limbs, followed by giddiness or vertigo. Fracture contributed mainly in the serious injuries, most of them took medical aid, daily functions was affected by fall and its consequences and there was a large group suffering from the consequences of fall and the economic burden. Important risk factors for fall in the study population were frequent alcohol consumption in males and dizziness, physical activity was found to be protective against falls. Certain risk factors were found to be different in men and women.

Being the first case-control study on the risk factors for fall among elderly, this study gives us the much-needed data on the risk and protective factors for fall and its association in a rural Indian population. Also, it helped identify certain factors, like difficulty in walking, difficulty in negotiating stairs/steps, fear of fall, and the circumstances which could potentially serve as predictors of fall. Information from this study could be utilized to design targeted intervention measures aimed at preventing fall in this vulnerable age group. To better understand the prevalence, nature and trends of unintended injuries at population level in India, Community-based falls records and surveillance systems should be set up. ${ }^{22}$

\subsection{Limitation of the study}

Being a retrospective study, serious consequences of fall such as death was not captured in the study. The exposure variables and the cost estimation were self-reported and could have could have reporting and recall bias. Since our cases and controls were matched for age and gender the effect of those variables were not studied.

\section{Funding}

This research was covered under 2010 Fluid Grant Studies, from Christian Medical College, Vellore to the First author as a Postgraduate Student of Epidemiology, Department of Community Health, Christian 
Medical College, Vellore, Tamil Nadu, 632,004, India.

\section{Declaration of competing interest}

The authors have no conflict of interest.

\section{Acknowledgements}

We would like to express our gratitude to Dr. KR John and Dr. Kurien George former Head of Community Medicne, CMC Vellore for their support and guidance. The support staff of the Community Health Training Centre (CHTC), Social workers at Community Health \& Development (CHAD), CMC Vellore, and to all the Elderly participants of the study from Kaniyambadi Block.

\section{References}

1 editor World Health Organization. In: WHO Global Report on Falls Prevention in Older Age. Geneva, Switzerland: World Health Organization; 2008.

2 Jeon MY, Jeong H, Petrofsky J, Lee H, Yim J. Effects of a randomized controlled recurrent fall prevention program on risk factors for falls in frail elderly living at home in rural communities. Med Sci Mon Int Med J Exp Clin Res. 2014 Nov 14;20: 2283-2291.

3 Gschwind YJ, Kressig RW, Lacroix A, Muehlbauer T, Pfenninger B, Granacher U. A best practice falls prevention exercise program to improve balance, strength/ power, and psychosocial health in older adults: study protocol for a randomized controlled trial. BMC Geriatr. 2013 Oct 9;13:105.

4 Jeon M, Gu MO, Yim J. Comparison of walking, muscle strength, balance, and fear of falling between repeated fall group, one-time fall group, and nonfall group of the elderly receiving home care service. Asian Nurs Res. 2017 Dec;11(4):290-296.

5 Maneeprom N, Taneepanichskul S, Panza A, Suputtitada A. Effectiveness of robotics fall prevention program among elderly in senior housings, Bangkok, Thailand: a quasi-experimental study. Clin Interv Aging. 2019 Feb 18;14:335-346.

6 Pitchai P, Dedhia HB, Bhandari N, Krishnan D, D'Souza NRJ, Bellara JM. Prevalence, risk factors, circumstances for falls and level of functional independence among geriatric population - a descriptive study. Indian J Publ Health. 2019 Jan 1;63(1):21.

7 Agarwalla R, Saikia AM, Pathak R, Islam F, Borah M, Parashar M. A cross sectional study on assessment of falls in community dwelling elderly of Assam. Natl $J$ Community Med. 2016;7:368-371.
8 Schoene D, Heller C, Aung YN, Sieber CC, Kemmler W, Freiberger E. A systematic review on the influence of fear of falling on quality of life in older people: is there a role for falls? Clin Interv Aging. 2019 Apr 24;14:701-719.

9 Hosseini L, Kargozar E, Sharifi F, Negarandeh R, Memari A-H, Navab E. Tai Chi Chuan can improve balance and reduce fear of falling in community dwelling older adults: a randomized control trial. J Exerc Rehabil. 2018 Dec 27;14(6):1024-1031.

10 Zhao M, Li S, Xu Y, Su X, Jiang H. Developing a scoring model to predict the risk of injurious falls in elderly patients: a retrospective case-control study in multicenter acute hospitals. Clin Interv Aging. 2020;15:1767-1778.

11 Khalifa M. Improving patient safety by reducing falls in hospitals among the elderly: a review of successful strategies. Stud Health Technol Inf. 2019 Jul 4;262:340-343.

12 Sirohi A, Kaur R, Goswami AK, Mani K, Nongkynrih B, Gupta SK. A study of falls among elderly persons in a rural area of Haryana. Indian J Publ Health. 2017 Apr 1;61 (2):99.

13 Almeida CWL, Castro CHM, Pedreira PG, Heymann RE, Szejnfeld VL. Percentage height of center of mass is associated with the risk of falls among elderly women: a case-control study. Gait Posture. 2011 Jun 1;34(2):208-212.

14 Kumar A, Delbaere K, Zijlstra GAR, et al. Exercise for reducing fear of falling in older people living in the community: cochrane systematic review and meta-analysis. Age Ageing. 2016 May 1;45(3):345-352.

15 Zijlstra GAR, van Haastregt JCM, Ambergen T, et al. Effects of a multicomponent cognitive behavioral group intervention on fear of falling and activity avoidance in community-dwelling older adults: results of a randomized controlled trial. J Am Geriatr Soc. 2009 Nov;57(11):2020-2028.

16 Osteoporosis: pathogenesis, diagnosis, prevention and management - PubMed [cited 2021 Jun 17]. Available from: https://pubmed.ncbi.nlm.nih.gov/8435050/.

17 Thomas E, Battaglia G, Patti A, et al. Physical activity programs for balance and fall prevention in elderly. Medicine (Baltim). 2019 Jul 5;98(27), e16218.

18 Hansson EE, Magnusson M. Vestibular asymmetry predicts falls among elderly patients with multi-sensory dizziness. BMC Geriatr. 2013 Dec;13(1):1-6.

19 Zia A, Kamaruzzaman SB, Tan MP. Polypharmacy and falls in older people: balancing evidence-based medicine against falls risk. PGM (Postgrad Med). 2015 May 4;127(3): 330-337.

20 Ram A, Victor CP, Christy H, Hembrom S, Cherian AG, Mohan VR. Domestic violence and its determinants among 15-49-year-old women in a rural block in South India. Indian J Community Med: Off Publ Indian Assoc Prev Soc Med. 2019 Oct;44(4):362.

21 Sibley KM, Voth J, Munce SE, Straus SE, Jaglal SB. Chronic disease and falls in community-dwelling Canadians over 65 years old: a population-based study exploring associations with number and pattern of chronic conditions. BMC Geriatr. 2014;14:22.

22 Kaur R, Kalaivani M, Goel AD, Goswami AK, Nongkynrih B, Gupta SK. Burden of falls among elderly persons in India: a systematic review and meta-analysis. Natl Med $J$ India. 2020 Aug;33(4):195-200. 